\title{
Autobiografias trans: um levante em formação
}

\author{
Transgender autobiographies: a developing uprising
}

Autobiografías trans: un levantamiento en formación

Leocádia Aparecida Chaves*

\section{Resumo}

Neste artigo, discuto a produção autobiográfica de autoria trans no Brasil contemporâneo como estratégia de resistência e organização. Trata-se de uma produção, pelos critérios metodológicos estabelecidos, nascida em 1982 e avolumada a partir de 2011, compondo um universo de quinze obras até o ano de 2019. Para discutir essas autorrepresentações como instrumento radical de luta e de luto, contextualizo-as no campo literário contemporâneo, que historicamente confirma-se como transfóbico, seja por representações estigmatizadas e estereotipadas dessa identidade e/ou sua ausência, seja pela exclusão de pessoas trans na instância da autoria. Buscando identificar as estratégias de resistência e organização, proponho acessar as obras selecionadas pela analítica do cuíerlombismo, ainda que em distensões. A partir dessa abordagem cartográfica, destaco o narrar-se como um arquivar-se, o que tanto permite a formação, no espaço literário, de uma comunidade de afeto, de partilha, quanto se constituir como política e dever de memória.

Palavras-chave: autobiografia, autoria trans, campo literário contemporâneo, Cuíerlombismo.

\section{Abstract}

This paper, discusses the autobiographical production of transgender authorship in contemporary Brazil as a strategy of resistance and organization. By the methodological criteria used, this production begins in 1982 and enlarges after 2011, forming a corpus of fifteen works until 2019. To discuss these self-representations as a radical tool of resistance and grief, they have been contextualized in the contemporary literary field, that historically has confirmed itself as transphobic, be it due to stigmatized and stereotyped representations or its absence, be it due to the exclusion of transgender people from the instance of authorship. Aiming to identify the resistance and organization strategies, I suggest accessing the selected works through the lens of cuíerlombismo, even with distensions. Based on this cartographic approach, I highlight the act of narrating themselves as the act of archiving themselves, which both allows the constitution, in the literary space, of a community of affection and sharing, and a way of development as a politics and a duty of memory.

Keywords: cautobiography, transgender authorship, contemporary literary field, Cuíerlombismo.

\section{Resumen}

En este artículo, discuto la producción autobiográfica de autoría trans en el Brasil contemporáneo como estrategia de resistencia y organización. Se trata de una producción, según los criterios metodológicos establecidos, originada en 1982 y ampliada a partir de 2011, por lo que compone un universo de quince obras hasta el año 2019. Para discutir las autorrepresentaciones como instrumento radical de lucha y luto, las contextualizo en el campo literario contemporáneo que históricamente se confirma como transfóbico ya sea por representaciones estigmatizadas y estereotipadas de dicha identidad y/o ausencia, ya sea por la exclusión de personas trans de la instancia de la autoría. En busca de identificar las estrategias de resistencia y organización, propongo acceder a las obras seleccionadas mediante la analítica del cuíerlombismo aunque en distensiones. Con base en dicho abordaje cartográfico, subrayo el narrarse como un archivarse, lo cual permite tanto la formación, en el espacio literario, de una comunidad de afecto, como de constituirse como política y deber de memoria.

Palabras clave: autobiografía, autoría trans, campo literario contemporáneo, Cuíerlombismo.

\footnotetext{
*Universidade de Brasília (UnB), Brasília, DF, Brasil. Đorcid.org/0000-0002-6205-6304. E-mail: leocadiachaves@gmail.com
} 
Mas a cada vez que a travessia é possível, o mapa de uma nova sociedade começa a ser desenhado, com novas formas de produção e de reprodução de vida.

Preciado

\section{Sob um mapa de estigmas e ausências}

Neste artigo, discuto a produção autobiográfica de autoria trans no Brasil contemporâneo como estratégia de resistência e organização no campo literário. Recorte motivado, de forma determinante, pelas constatações e reflexões apresentadas por Regina Dalcastagnè (2021), ${ }^{1}$ e Luiz Henrique Moreira Soares e Rosiney Aparecida Lopes (2017) sobre a produção romanesca publicada pelas grandes editoras no Brasil contemporâneo que, de forma engendrada, via de regra, revelam-se (re)produtoras de múltiplas violências do/no campo literário (Bourdieu, 1993) $)^{2}$ dentre elas a transfobia.

Se o "censo" literário efetivado por Dalcastagnè (2021) - a partir de 689 romances de autores brasileiros publicados pelas mais importantes editoras do país entre 1965 e 1979 e entre 1990 e 2014 - apresenta-nos um cenário dominado, tanto pela instância da autoria, quanto pela de personagens representadas por aqueles que sempre detiverem o poder de falar e serem ouvidos (Spivak, 2010) em nosso país (homens, ${ }^{3}$ brancos, aproximando-se ou já entrando na média idade, moradores do eixo Rio-São Paulo), a pesquisa de Soares e Lopes (2017), partindo de metodologia semelhante, dedica-se à análise da representação travesti em romances publicados entre os anos de 2000-2016. Como resultado, em convergência com a perspectiva analítica de Dalcastagnè (2021), Soares e Lopes (2017) constatam que a maioria dos romances que compõem o objeto do estudo foi escrita por homens - provavelmente cis -, que por sua vez monopolizam - por meio de seus narradores - os lugares de fala no interior das narrativas. Do total de trinta e nove romances, e de cinquenta personagens travestis, apenas dezoito são representadas como protagonistas; as demais ocupam espaços de exclusão social com representações que orbitam entre corpos mortos, assassinas perigosas, seres angustiados, suicidas ou sujeitos não nomeáveis. ${ }^{4}$ Dados explicitamente confirmadores de que as existências transvestigênere ${ }^{5}$ (a partir de agora identificadas como trans) em nossa sociedade são violentadas tanto na instância da representação quanto na da autoria, o que legitima o regime de exceção transfóbico (Jesus, 2013) também no/pelo literário:

constatação que não deve causar espanto, já que ele se insere num universo social que é também extremamente excludente. Falta ao romance brasileiro contemporâneo, como os números da pesquisa indicam de maneira eloquente, incorporar as vivências, os dramas, as opressões, mas também as fantasias, as esperanças e as utopias dos grupos sociais marginalizados, sejam eles definidos por classe, por gênero, por raça e cor, por orientação sexual ou por qualquer outro critério (Dalcastagnè, 2021, p. 140).

Porém, como Regina Dalcastagnè (2012) enuncia, o campo literário contemporâneo também tem sido um território contestado por uma multiplicidade de vozes que, vinculadas a grupos sociais historicamente subalternizados em nossa sociedade, não tem sucumbido a esses extermínios. Como discute Judith Butler (2018), mesmo que se trate de vidas reconhecidas como

\footnotetext{
${ }^{1}$ A autora sublinha que, neste trabalho, apresenta as segunda e terceira fases de uma pesquisa cujos dados iniciais (relativos ao período de 1990 a 2004) foram publicados na revista Estudos de Literatura Brasileira Contemporânea (Dalcastagnè, 2005).

${ }^{2}$ Dalcastagnè (2021), a partir de Bourdieu (1993), define campo literário como uma rede ou uma configuração de relações objetivas entre posições; uma mecânica de funcionamento que engloba: formas de consagração de obras e de seus produtores, suas produtoras, aparatos de leitura crítica e intepretação.

3 “Nos dados da pesquisa, trabalhamos com 'sexo' como marcador biológico do dimorfismo sexual macho/fêmea, desconectado dos papéis de gênero e da orientação sexual” (Dalcastagnè, 2021, p. 123).

${ }^{4}$ Em confirmação, acrescentam-se o estudo e as reflexões de Amara Moira (2018), e Schwantes e Chaves (2019).

${ }^{5}$ De acordo com Siqueira (2017), o conceito de identidade transvestigênere funciona como uma tentativa de abarcar as identidades trans (homens, mulheres e não-bináries) e travestis a fim de evitar intransigências continuamente (re)produzidas pela cisnormatividade.
} 
destituídas de direitos (à vida, à saúde, à educação, à cultura, ao trabalho, à família, por exemplo), ainda se trata de vidas que estão dentro da esfera do político, portanto, nunca reduzidas à mera existência, mas, com frequência, como enraivecidas, indignadas e revoltadas, opondo resistência. Resistência que se concretiza, muitas vezes, por ações múltiplas, variadas e criativas, muito distanciadas de um heroísmo extraordinário (Das, 2007), e igualmente capazes de garantir, no "como é possível", às margens do campo literário (Dalcastagnè, 2021), a defesa de que

corpos sem conformidade [...], assim como aqueles que se conformam bem demais (e a um alto custo) possam respirar e se mover mais livremente nos espaços públicos e privados, assim como em todas as zonas nas quais esses espaços se cruzam e se confundem (Butler, 2018, p. 40).

\section{A identificação de um levante}

Considerando a perspectiva acima indicada, é possível identificar, na produção autobiográfica de autoria trans no Brasil contemporâneo, um gesto de resistência enraivecida, indignada e revoltada contra todo o cistema ${ }^{6}$ de exclusão literário. Neste "como é possível" é que, desde 1982, vozes tão múltiplas entre si - travestis, mulheres e homens trans, pessoas trans não-binárias - vêm ocupando o território da literatura brasileira contemporânea e garantindo, pela autorrepresentação, outros imaginares sobre suas existências, obviamente denunciadoras de estigmas abjetificadores, monstrualizadores, criminizadores e patologizadores criados sobre si (Goffman, 1988; Leite Junior, 2012).

Essa produção vem irrompendo nos últimos quarenta anos também em múltiplos trânsitos, dentre eles a da própria escrita "identitária", inscrita no gênero textual autobiografia, de forma exponencial na última década do século XXI, quando vimos florescer uma produção ficcional em prosa e poesia de autoria trans com forte teor testemunhal. Universo de escritas que me levou afiliar aos parâmetros estabelecidos por Philipe Lejeune (2014), que de forma mais ortodoxa, se por um lado me permitiu uma determinada seleção; por outro, impôs limites.

Devo ressalvar, entretanto, que, apesar dos parâmetros mais ortodoxos da seleção efetuada, fi-lo com algumas distensões. Quanto aos critérios estabelecidos por Lejeune (2014) e tomados como ponto de partida para o trabalho, considerei os seguintes: 1) a obra ter sido publicada como resultado de uma produção autoral; 2) o nome do autor ou da autora coincidir com o nome do narrador-protagonista; 3) o engendramento do contrato de verdade ser explicitado, ou seja, o estabelecimento de um pacto de verdade com a leitora ou o leitor, e, por último, 4) a enunciação ser realizada pelo autor-narrador, autora-narradora, a partir do questionamento compulsório da identidade de gênero e, consequentemente, a textualidade se estabelecer a partir da experiência da transição. Esses parâmetros levaram-me a quinze obras, sendo treze narrativas individuais e duas coletivas: 1) A queda para o alto (1982), de Herzer7; 2) Erro de pessoa: Joana ou João?: o depoimento de um transexual brasileiro que, nascido mulher, finalmente se realizou como homem (1984), de João W. Nery; 3) Meu corpo, minha prisão: autobiografia de um transexual (1985), de Loris Ádreon; 4) Liberdade ainda que profana (1998), de Ruddy; 5) Nem tão bela, nem tão louca (2007), de Ruddy Pinho; 6) Olhares de Claudia Wonder: crônicas e outras histórias (2008), de Claudia Wonder; 7) Viagem solitária: memórias de um transexual trinta anos depois (2011), de João W. Nery; 8) Eu trans: a alça da bolsa - Relatos de um transexual (2014), de Jô Lessa; 9) Meu nome é Amanda: \#trans\#mandycandy\#youtube (2016), de Amanda Guimarães; 10) E se eu fosse puta (2016), de Amara Moira; 11) Vidas trans: a coragem de existir (2017), de T. Brant, Amara Moira, João W.

\footnotetext{
${ }^{6}$ Viviane S. Vergueiro (2015), ao discutir o modus operandi de dominação do colonizador europeu na América, desnuda como o sexismo - estereotipias e atribuição de valor, poder ao gênero masculino e feminino - fundou o patriarcado. A partir dessa discussão, traz ao debate o conceito de cissexismo, operador potente para que possamos desnudar os mecanismos de opressão da cisgeneridade sexista sobre aqueles reconhecidos como divergentes da norma. A partir dessa compreensão, refere-se às estruturas de poder, usando em corruptela a denominação "cistema", na grafia com c, que tomo como referência, por exemplo, para identificar o campo literário como cistema literário.

${ }^{7}$ Faz-se aqui necessária uma ressalva. Como destaca Amara Moira em entrevista à Revista Crioula (Moira, 2019), embora Herzer não se tenha autoidentificado como homem trans em sua narrativa, enuncia-se na ruptura com o gênero feminino compulsoriamente determinado para a sua existência, portanto, ainda que não avoque a identidade trans, ao se reconhecer homem, se reconhece na transição identitária, o que nos autoriza estabelecer a sua obra como um marco quanto a essa produção no Brasil.
} 
Nery e Márcia Rocha; 12) Trinta anos de reclusão e as memórias de Porcina D'Alessandro (2017), de Porcina D'Alessandro; 13) Nós, trans: escrevivências de resistência (2017), organizado por Maria Léo Araruna; 14) A vida de um transgênero (2018), de Téhh Queiroz, e 15) Velhice transviada: memórias e reflexões (2019), de João W. Nery.

Quanto ao movimento de distensão do conceito proposto por Philippe Lejeune (2014), o faço "autorizada" tanto pelas reflexões do próprio teórico, que, ao propor as fronteiras para o gênero literário da autobiografia, também o faz como convite para o diálogo e (re)formulações, quanto pelas observações de Luiz Antônio Marcuschi (2005), que nos lembra que os gêneros textuais são "eventos textuais altamente maleáveis, dinâmicos e plásticos" (p. 19) ao longo da história humana. Tais reflexões permitiram-me incluir no corpus as obras: Olhares de Claudia Wonder: crônicas e outras histórias (2008), Nós, trans: escrevivências de resistência (2017), organizada por Maria Léo Araruna, e Velhice transviada: memórias e reflexões, de João W. Nery (2019), que se distanciavam de alguns dos pré-requisitos estabelecidos por Lejeune (2014).

\section{O levante também como um abrigo}

A produção literária de autoria trans pode ser identificada como um levante de caráter cuíerlombista, conforme propõe Tatiana Nascimento (2018a, 2018b) ao discutir a produção ficcional LGBTQI+ preta e a crítica sobre ela, pois da perspectiva de reflexão apresentada pela teórica, determinadas produções guardam a potência de se fazerem abrigo: resistência e organização no campo literário.

Essa analítica, conforme explica a teórica, nasce do diálogo com o conceito de quilombismo, de Abdias do Nascimento (1980/2002) e Beatriz Nascimento (2006), e das discussões pautadas por teóricos e ativistas do movimento cuíer brasileiro - recriação e refundação do movimento queer, -8 como Jota Mombaça, Bibi Abigail e Marisa Lobo. Do quilombismo pautado pelos dois primeiros intelectuais, Tatiana Nascimento expande a concepção "território de resistência e organização" dos quilombos tradicionais para a produção literária e a sua crítica. Como explica, se lá a resistência e a organização de egressos ou fugitivos da escravidão se efetivaram por meio da instituição física dos aldeamentos, na contemporaneidade efetivar-se-á no espaço literário, onde os/as "cuíerlombolas" contemporâneos/as garantirão espaço para existir física, subjetiva e literariamente (Nascimento, 2018a; 2018b), portanto, contestando o cistema literário também perpetuador de extermínios colonizadores.

Como sublinha a intelectual, o próprio abrasileiramento do conceito queer enfatiza na grafia o seu entrelugar - quilombo e queer - e inclusivamente comporta alterações ortográficas: "cuíerlombismo" (terminologia escolhida para uso neste estudo), "cuírlombismo", "kuíerlombismo". Uma recriação conceitual que tanto revela um procedimento teóricometodológico quanto estimula uma guinada no campo dos estudos literários e de sua produção para além do paradigma da dor: denúncia e raiva.

Percebo como vigorosa essa concepção para o reconhecimento da potência cuíerlombista da produção autobiográfica trans no Brasil, uma vez que me permite reconhecê-la como narrativas criadas para que seus autores e autoras possam existir física, subjetiva e literariamente (Nascimento, 2018a; 2018b), pois viabilizadoras de um narrar-se prenhe de mundos novos, im ou possíveis, utópicos, "diz-tópicos" (Nascimento, 2018a): um lugar de dizer e, por isso, não só resistência, mas sonho, afeto e abrigo: organização.

Porém, ao manejar a analítica de Nascimento (2018a; 2018b), também o faço em distensão, no que tange à raça da autoria, ao gênero textual e ao teor literário, pois, enquanto a intelectual territorializa o cuíerlombismo como resistência e organização para a produção ficcional - prosa e poesia - de autoria negra e/ou LGBTQI+ que "desorbite o paradigma da dor", volto-me para a produção autobiográfica, ancorada na dor, de pessoas não-negras dissidentes de gênero. $O$

\footnotetext{
${ }^{8} \mathrm{O}$ termo queer (traduzido como esdrúxulo, vadio), imputado de forma a tornar abjetas as identidades sexuais nos países de língua inglesa nas décadas de 1980-1990, passou a ser avocado como potência subversiva ao status quo por Teresa de Lauretis (1991), quando designou como queer os estudos pós-estruturalistas voltados para a temática.
} 
que se justifica pelo reconhecimento de que, ainda que essas escritas sejam produzidas por pessoas salvas do genocídio racista, estão territorializadas como vidas não vivíveis pelos supremacismos coloniais e colonizadores e por isso alvo do genocídio transfóbico (Jesus, 2013).

As distensões que executo no conceito de cuíerlombismo para analisar a produção de autoria trans no Brasil efetivam-se a partir das reflexões de Patricia Hill Collins (2019), Bell Hooks (2019a) e Audre Lorde (2020), todas dedicadas a pensar a potência revolucionária da produção escrita de mulheres negras norte-americanas, também em processos de subalternização. Quanto à potência de resistência e organização por meio do gênero autobiográfico, Patricia Hill Collins $(2019)^{9}$ destaca os processos de autodefinição e de autovalorização como quebra do isolamento e do fortalecimento comunitário. Nesse mesmo sentido, Jaqueline Gomes de Jesus (2010) enfatiza a autodefinição como garantia primeva para se reconhecer e ser reconhecido como humano, num processo que vai além de uma identidade civil - apesar de se vincular a ela -, pois se trata de reconhecer-se como uma pessoa, sujeito de direitos, dentre eles, o de ser respeitado no seu processo de autorreconhecimento. ${ }^{10}$ Já a autovalorização permite a formação de autoestima individual com impacto comunitário. Portanto, processos subjetivos fundamentais para a construção de suas narrativas pessoais, bem como para a (re)construção de um imaginário social sobre o grupo a que se vincula, uma vez que de suas agências ${ }^{11}$ acabam por colocar em xeque definições de controle sobre suas existências. Em consonância com Collins (2019), Bell Hooks (2019a) sublinha:

Como literatura de resistência, narrativas confessionais de pessoas negras são didáticas. Mais do que qualquer outro gênero textual, a produção de narrativas confessionais honestas pelas mulheres que estão lutando por autorrealização e para se tornar sujeitas radicais são necessárias como guias, textos que reforçam o companheirismo entre nós. Eu preciso não me sentir isolada e saber que existem outras companheiras com experiências semelhantes. Eu aprendo com suas estratégias de resistência e com os relatos de seus erros (p. 125-126).

Conforme me ajudam a pensar Collins e Hooks, trata-se aqui de uma produção capaz de se estabelecer como guia, reforçando o companheirismo entre as pessoas que comungam desse mesmo "lugar", ou seja, abrigo para o compartilhamento de estratégias de resistência e relatos de erro, próprio de uma vivência comunitária. Collins (2019) enfatiza ainda que se trata de um conhecimento único, pois produzido por quem vive, diferentemente do produzido por quem apenas lê ou pensa sobre o tema. Nesse mesmo sentido, Hooks (2019a) acrescenta:

Ainda que o número de romances publicados por mulheres negras tenha aumentado, essas obras não podem substituir a teoria ou a narrativa autobiográfica. Mulheres negras radicais precisam contar nossas histórias; nunca é suficiente documentar nossas experiências (p. 126).

Assim, se o cuíerlombismo pensado por Nascimento (2018a; 2018b) está territorializado numa perspectiva que desorbite o paradigma da dor, por ser meio fraturador de estigmas e subalternizações, a produção autobiográfica trans, a despeito de nascer "do e no paradigma da dor", também permite romper com análises perpetuadoras de estigmas e subalternizações, como demonstrarei. Além. Guardam, rebeldemente, a potência de nos revelar o quanto o

\footnotetext{
${ }^{9}$ Saliento que Collins (2019) e Hooks (2019a) realizam suas análises a partir da produção de relatos de mulheres negras nos Estados Unidos, que, sob a opressão racista, sexista, classista, usam a autobiografia como estratégia de organização e resistência, o que me permite deslocar suas análises para a discussão proposta neste estudo, uma vez que me volto para a produção de um grupo também minorizado em nossa sociedade, o de pessoas trans.

${ }^{10}$ Vale registrar que esse direito só foi conquistado, ao menos juridicamente, mais recentemente, quando, em 2018, o Supremo Tribunal Federal, por meio de uma Ação Direta de Inconstitucionalidade (ADI) 4275, reconheceu o direito de alteração do prenome e gênero no registro civil via procedimento cartorial, sem a necessidade de realização de cirurgia de mudança de sexo, ato ou laudos médicos e psicológicos. Reconhecendo, portanto, a partir do princípio constitucional da garantia da dignidade humana, o direito ao autorreconhecimento identitário. Disponível em: http://www.stf.jus.br/portal/cms/verNoticiaDetalhe.asp?idConteudo=371085. Acesso em: 10 abr. 2018.

${ }^{11}$ De acordo com Norman Long e Jan Douwe van der Ploeg (2011), "Em termos gerais, a noção de agência atribui ao ator individual a capacidade de processar a experiência social e de delinear formas de enfrentar a vida, mesmo sob as mais extremas formas de coerção. Dentro dos limites da informação, da incerteza e de outras restrições (físicas, normativas ou político-econômicas) existentes, os atores sociais são 'detentores de conhecimento' e 'capazes"' (p. 21).
} 
padrão compulsório da cisheteronormatividade violenta, ainda que em graus diversos, a todas e todos nós, ainda que seja letal apenas para uma parte de nossa sociedade.

Para evidenciar essa produção como sonho e semente por meio da dor e da raiva, faço-o em diálogo com as discussões e reflexões apresentadas por Bell Hooks (2019a) e Audre Lorde (2020), que, dedicadas a discutir os mecanismos de opressão coloniais sobre minorias identitárias, por modos e meios distintos, enfatizam o falar da dor, da raiva, como uma expressão de poder, transformando a não-escuta de suas vozes em linguagem e ação. Bell Hooks (2019a; 2019b) sublinha que é preciso garantir espaço para que os grupos subalternizados encontrem formas de nomear suas dores para que também possam articular o prazer. Em confirmação, destaca, como exemplo máximo, que não raras vezes lideranças do movimento negro estadunidense acham difícil expressar suas experiências de dor:

Mesmo aqueles que estão, com razão, empenhados na luta pela libertação dos negros, que sentem ter descolonizado suas mentes, com frequência acham difícil "falar" da nossa experiência. Quanto mais dolorosas as questões que confrontamos, maior a nossa falta de articulação (Hooks, 2019a, p. 32).

Isso porque, parafraseando a intelectual, para que possam falar sobre suas dores e articular seus prazeres, essas pessoas deverão romper com os modelos hegemônicos de se verem, se pensarem e serem, o que bloqueia suas capacidades de inventar modos de se verem, se descreverem e que sejam libertadores. Um desafio que também se impõe às pessoas trans em nossa sociedade, pois expressar suas existências é se dizer sob um cistema transfóbico, portanto, sob um modelo que se impõe como hegemônico quanto ao se ver, se pensar, se descrever como humano. Por isso este desafio, o da escrita autobiográfica, acaba por se transformar num exercício viabilizador para que também possam articular seus prazeres, conquistas, desejos, sonhos subjetivos e/ou objetivos.

Por essa perspectiva, ao falarem suas experiências, colocam em ação a linguagem a favor de novas formas de se ver e falar a transvestigeneridade e, consequentemente, fraturar representações de domínio sobre suas existências, produzir subversões, seja nas formas como dizem suas dores, seja nas formas como articulam seus prazeres, não restritas a criticar o status quo, mas também como um meio para apresentar alternativas críticas e transformadoras de suas visões de mundo (Hooks, 2019a; 2019b).

Portanto, parafraseando Lorde, para pessoas em situação de opressão, como as mulheres negras e/ou lésbicas, como a própria Audre Lorde, escrever a dor e a raiva não é uma opção, é um meio, uma vez que suportarão a intimidade da investigação e permitirão o florescimento dentro dela: "Os horizontes mais longínquos das nossas esperanças e dos nossos medos são pavimentados pelos nossos poemas, esculpidos nas rochas que são nossas experiências diárias" (Lorde, 2020, p. 47). É uma jornada que lhes dará acesso a seus medos e esperanças e, nesse movimento, explorá-los com honestidade, o que permitirá que os aceitem, tornando-os santuários e territórios férteis para as ideias mais radicais e ousadas (Lorde, 2020).

Semelhante grandeza também se revela nas autobiografias trans, pois seus autores e suas autoras têm manejado a raiva para agir: escrever suas histórias de vida, de (re)existência, que, ao fim e ao cabo, esbarram nas nossas próprias vidas, uma vez que, reconheçamos ou não, cada um/uma de nós somos corresponsáveis pela manutenção do status quo transfóbico em nossa sociedade. Portanto, um ato que liberta e dá força, um movimento vital, pois impeditivo para que não releguem ao lixo suas visões e percepções acerca de suas vidas; um ato rebelde, vital, pois impeditivo para que nós, da crítica literária, não releguemos ao lixo nossa corresponsabilidade diante do regime de exceção (re)produzido também na crítica literária cisgênera que, via de regra, tem inviabilizado tanto a produção de autoria trans quanto viabilizado transfobias no e pelo campo literário. A partir dessas perspectivas, enfatizo o desafio e o convite posto para nós, da crítica literária: que saibamos ouvir essa dor, essa raiva distanciada do sadismo supremacista, que vem garantido, por diversos meios, que suas enunciações sejam limitadas a um "choro" desprezível, que muitas vezes sequer ofertamos aos animais sarnentos (Nascimento, 2019). 
É nessa trilha de pensamento que assento o levante autobiográfico trans em três nucleamentos histórico-temporais: anos de 1980 - fim da ditadura civil-militar -, composto de três obras; anos de 1990 a 2010 - reconstrução da democracia brasileira -, composto de três obras; e anos de 2011 a 2019 - recessão da democracia brasileira -, composto de nove obras; estratégia que me permitiu estabelecer eixos temáticos de discussão para cada um deles, como apresentarei adiante.

\section{Furando o bloqueio (1982-1985)}

É sob um duplo regime de opressão - o da ditadura e o cisheteronormativador - que Anderson Herzer, João Walter Nery e Loris Ádreon decidem escrever e publicar a experiência de "existir na dissidência quanto ao gênero", e desse lugar, de quem vive e sabe, revelar os caminhos percorridos para a transição de gênero. São escritas que corajosamente "furam o bloqueio" e interpelam as suas leitoras e os seus leitores sobre a violência da compulsoriedade de gênero estabelecida para suas vidas num contexto de perseguição e criminalização (Quinalha, 2021).

Sublinha-se que o texto autobiográfico de Anderson Herzer nasce a convite, em fins dos anos de 1970, quando o autor já se autorreconhecia como poeta e assim era reconhecido nas unidades da Fundação Estadual para o Bem Estar do Menor (Febem), onde estivera internado na cidade de São Paulo nos últimos anos de sua vida. Uma escrita que nasce rebelião, pois, numa atitude máxima de coragem, além de denunciar as violências que eram infligidas às jovens internas pelo simples fato de não vivenciarem seus desejos e gêneros conforme o padrão, o faz a partir de uma crítica contundente: a falácia do padrão biologizante para a identidade de gênero masculina, gênero com o qual passou a se autorreconhecer na juventude. Importante notar ainda que, embora o autor não se narre a partir de discursividades médicas (como acontece nas obras de João W. Nery e Loris Ádreon), ao contestar "as versões dadas sobre si", segue confirmando: "Para mim eu era um rapaz em fase de adolescente, e para alguns, um caso que deveria ser tratado clinicamente" (Herzer, 2007, p. 108).

Uma enunciação vital para outras e outros que, como ele vivenciando a transição de gênero ou a inconformidade com a compulsoriedade de nascimento, "encontrassem" abrigo para que a autoidentificação prevalecesse como a verdade; gesto próprio de um cuíerlombola que, à revelia do cistema de exceção "encarnado" pela Febem, autoafirma-se, autovaloriza-se como um homem. Questiona "como seria o mundo se todos os homens trouxessem sua virtude, seu caráter no formato de duas bolas?" (Herzer, 2007, p. 110).

João Walter Nery - jovem, branco, de classe média carioca, graduado em Psicologia escreve Erro de pessoa: Joana ou João?: o depoimento de um transexual brasileiro (1984), como enuncia, para "documentar as sensações que f [oi] tendo das vivências ambíguas no transcurso da [sua] vida - o de ter nascido homem, aprisionado num corpo de mulher" (Nery, 1984, p. 7). E o faz, exatamente no momento em que se recupera das cirurgias de redesignação de sexo ainda proibidas e criminalizadas no Brasil. ${ }^{12}$ Realidade que o forçará - como explicita - a usar nomes fictícios em alguns lugares e com algumas pessoas. Dados esses "decodificados" na sua segunda autobiografia, Viagem solitária: memórias de um transexual trinta anos depois (2011), publicada passados vinte e sete anos da edição da primeira obra, já num contexto de liberdade democrática. Portanto, irá escrever a sua história de vida num período que poderia ser de completa realização pessoal, como desabafa, mas que se realiza num contexto de irrealização de sua própria existência, uma vez que, ao transitar de gênero clandestinamente - único meio possível -, perdera o direito aos documentos civis e curriculares, ${ }^{13}$ passando a "inexistir". Entretanto, essa "inexistência" tornou-se motivadora para o seu gesto de rebeldia literária, impelindo-o a descrever uma jornada de descobertas, pesquisas e reflexões, dentre elas a de ter

\footnotetext{
${ }^{12}$ Sobre isso, ver: https://projetocolabora.com.br/ods1/cirurgias-de-mudanca-de-sexo/attachment/amador/. Acesso em: 20 mar. 2018.

13 Nota-se que, mesmo com o fim da Ditadura, embora a Constituição de 1988 proibisse qualquer forma de discriminação, a retificação registral para pessoas trans, por meio judicial, só se tornou possível, em fins dos anos de 1990, quando o Conselho Federal de Medicina aprovou a Resolução $n^{\circ}$ 1.482/1997, autorizando os hospitais públicos ligados à pesquisa a realizarem, gratuitamente, a mudança de sexo (Carvalho, 2018).
} 
participado - como espectador e "exemplar vivo" - de um congresso internacional "clandestino" sobre transexualidade no interior de São Paulo, por volta de 1975-1976, o qual será minuciosamente "radiografado" em sua escrita. Uma narrativa que se constrói pedagogicamente para confirmar o sentimento de realização quanto às "cirurgias de adequação" de gênero como para indagar a violência da normatividade biologizante sobre corpos como o seu:

Desabafando, mas sem querer demonstrar abatimento pelas nefastas informações que acabara de ouvir [sobre as cirurgias], eu disse: - É uma opção muito idiota! Para ter um corpo compatível, amado e aceito, tenho de perder o prazer sexual! Não é estúpido ter que optar entre essas duas alternativas? Mas como não me resta outra, irei até o fim. De que me adianta ter prazer num lugar errado, de uma forma insatisfatória, num corpo trocado, sem conseguir me entregar inteiramente à pessoa que amo? (Nery, 1984, p. 232).

Meu corpo, minha prisão: autobiografia de um transexual (1985), de Loris Ádreon,14 publicada três anos após a obra de Herzer e um ano depois da de Nery, é uma escritura que já traz na sua abertura, "Nota explicativa de Loris Ádreon", uma declaração enfática:

Ao escrever a história de minha vida, detive meu pensamento numa firme e imutável idéia. Registrar para sempre a trajetória amarga que percorri desde meu nascimento, vivendo um papel em total discrepância com minha personalidade. A completa afinidade que descobri ter com o sexo feminino desde a mais tenra idade, me impelia sempre em direção a um comportamento que enfocava a feminilidade, embora vivesse cercada de repressão e violência, que visavam meu ajustamento compulsório a um comportamento masculino (Ádreon, 1985, p. 9).

Temos, dessa forma, uma narrativa que, junto às duas anteriormente publicadas, vem reforçar, nos anos iniciais de 1980, a otimização do espaço narrativo para a defesa do direito à existência transexual, neste caso pela voz de uma mulher trans, Loris Ádreon, que, diferentemente dos outros dois, dir-se-á da perspectiva do gênero feminino. Diferentemente de Herzer, que parece não ter tido condições de pesquisar/acessar informações sobre a transexualidade, e de Nery, que o faz fortuitamente em uma viagem pela Europa com pouco mais de 20 anos de idade, Loris o faz quando tinha aproximadamente doze anos de idade, por volta de 1972, curiosamente, numa cidade de interior do estado amazonense. Trata-se aqui de um apontamento importante em sua obra, pois, ao apresentar fatos e dados sobre a transexualidade, também apresenta como essas informações são acessadas pelo senso comum numa pequena cidade no norte do país, bem como na capital, que, moldados pela discursividade de que as identidades de gênero não são passíveis de (re)construções (Silva, 2014), perpetuam concepções que servem a hegemonias identitárias e múltiplas violências. Dessa forma, a narrativa de Ádreon, como a de Nery, organizadas a partir da consciência de uma existência nomeável - a transexualidade -, além de revelarem existências contrahegemônicas já validadas pelo discurso médico, mesmo que de forma patologizada, e igualmente perseguidas pelo Estado, revelam-se a si mesmos como agentes rebeldes e resistentes. Tal como no livro de Nery, a autora constrói um "roteiro anamnese", voltado à comprovação de se tratar de um caso diagnosticado pela medicina, portanto, "solucionável", permitindo-me identificar essas escritas como uma cartilha de quem delas se aproximar.

\section{Outras formas de se narrar trans (1998-2008)}

Será no contexto da redemocratização do estado brasileiro, não fortuitamente, que Ruddy Pinho e Claudia Wonder publicam suas escritas autobiográficas, escrituras que, por meios muito distintos, instauram uma radicalidade no tempo em que são publicadas, pois não estarão mais limitadas a se narrarem a partir do eixo da busca de um diagnóstico para efetivação do trânsito de gênero. Ao contrário, aqui vão "aparecer" pela autoafirmação. Se nas escritas de

\footnotetext{
${ }^{14}$ A autora registra que nascera no ano de 1960. Também é importante salientar que na nota de abertura explica que usa artigos, substantivos e adjetivos masculinos sobre si porque escreve a sua história de forma retrospectiva.
} 
Ruddy Pinho (Ruddy, 1998; Ruddy Pinho, 2007) a estrutura narrativa orbita em torno do seu sucesso profissional e otimismo diante da vida, "apesar dos pesares"; na de Wonder (2008) se revela uma outra força, a da ativista que, norteada pelo "Manifesto Travolaka", apresenta a sua história de vida juntamente à história de outras mulheres trans, igualmente "acreditáveis", ainda que sob múltiplas opressões.

Quanto à primeira autobiografia de Ruddy, Liberdade ainda que profana (1998), ocorre, como a autora enuncia, num momento em que celebra os trinta e cinco anos de carreira como cabeleireira:

Em janeiro de 98, dei uma grande festa, comemorando meus trinta e cinco anos de carreira. Fiz um grande happening no dia 29 de janeiro de 1998. Resolvi receber umas 500 pessoas, na própria galeria onde funciona o meu salão. Convidei drag-queens, a Rogéria, a Jane di Castro, Claudia Hazan (que me presenteou com uma dança do ventre), atores, atrizes, clientes, crianças, cachorro, um pouco de um tudo, como deve ser uma festa (Ruddy, 1998, p. 196).

Naquela circunstância é chancelada como autora e como tal enuncia que escreverá a sua narrativa autobiográfica: "É como escritora que dou meu testemunho de vida, tenho oito livros publicados, não sou apenas uma personalidade tecendo comentários ou contando situações. [...] Pretendo editar muitos" (Ruddy, 1998, p. 7). A busca pela "validação" parece ser mobilizada tanto para afirmar a qualidade de sua escrita, quanto a qualificação de sua vida: uma mulher trans que conquistou reconhecimento profissional, sucesso e patrimônio financeiro.

Já em Nem tão bela, nem tão louca (2007), a autora deter-se-á fundamentalmente nos fatos, experiências, conquistas e desafios vivenciados nos últimos anos do segundo milênio, dentre eles, as memórias de suas muitas viagens a Europa e aos Estados Unidos e o seu pleito a uma cadeira na Academia Brasileira de Letras. Elementos narrativos que parecem ser mobilizados tanto para confirmar a sua inserção social pelo consumo quanto para colocar em xeque, pela autoafirmação e autovalorização, o cistema que a violenta: "Quero com esse livro denunciar as alegrias e dificuldades em ser diferente e chegar à maturidade num país completamente ignorante a respeito das diferenças" (Ruddy Pinto, 2007, p. 11).

O livro Olhares de Claudia Wonder: crônicas e outras histórias, de Claudia Wonder (2008), reconhecido aqui como autobiográfico, difere de todas as outras obras deste corpus, pois é composto de uma variedade de gêneros textuais - crônicas, entrevistas, relatos biográficos e autobiográficos -, escritos e publicados entre 2003 e 2008, na revista G Magazine, um dos periódicos mais representativos e assumidamente militante pela causa LGBT no país durante o período que compreende os anos de 1997 a 2009 (Trevisan, 2018).

Como afirma na abertura do livro, a sua coluna representava "Um desafio e uma grande conquista", pois era um dos poucos espaços na imprensa nacional onde poderia pautar a questão trans, "um universo pouco conhecido, composto de travestis, transexuais, transgêneros e intersexos"15 (Wonder, 2008, p. 11) e, por esse modo,

elucidar as pessoas de um modo geral em relação a essa realidade, e também, com isso, repelir o preconceito que todo desconhecimento pode causar. Mas devo lembrar que ainda não existe uma "verdade" sobre esse tema, pois como o leitor poderá perceber, a cada momento surgem questões sexuais e de gênero. Trata-se de tema ainda carregado de muito tabu, em relação ao qual "autoridades" médicas, religiosas e políticas ainda discordam e, pior ainda, se mobilizam para continuar nos relegando, com todos os meios e mecanismos, à invisibilidade e à marginalidade (Wonder, 2008, p. 12).

Essa conquista lhe permitiu evidenciar questões essenciais sobre o universo trans feminino, bem como escrever e publicitar a sua versão sobre si; desse modo, se na coluna a sua história vai surgindo esparsamente ao longo dos anos, na obra, ela ganha visibilidade pela forma como o livro é organizado. Quanto à forma, importante destacar que, não fortuitamente, Wonder faz aparecer no

15 "A intersexualidade é um termo utilizado desde o século XX para o que se conhece no senso comum como hermafroditismo, isto é, a condição de indivíduos que nasceram com órgãos sexuais ambíguos. A linguagem biomédica marca tal condição como patológica, sendo compreendida como resultado de uma interação anormal dos fatores genéticos e hormonais ligados ao gênero no período pré-natal, e a denomina de distúrbio do desenvolvimento sexual (DDS)” (Gaudenzi, 2018, p. 1). 
livro - da página 1 à página 165 (já ao final) - uma sequência de sete fotografias que, intercalada aos textos, ajuda a "narrar" sua história de vida e a sua transição de gênero. Assim, entre a fotografia da abertura - a criança ainda "menino" - e a última - a mulher exuberante que se tornou -, a leitora ou o leitor acessam a história da ativista e o seu ativismo "disseminados" ao longo de toda a obra, numa composição autobiográfica articulada a "uma comunidade" de partilha, de afetos, que também enuncia e à qual se vincula (Nascimento, 2018a; 2018b).

\section{Ampliando a pauta dos direitos humanos (2011-2019)}

Neste terceiro nucleamento cuíerlombista, composto por nove obras: Viagem solitária: memórias de um transexual trinta anos depois, de João W. Nery (2011); Eu trans: a alça da bolsa Relatos de um transexual, de Jô Lessa (2014); Meu nome é Amanda: \#trans\#mandycandy\#youtube, de Amanda Guimarães (2016); E se eu fosse puta, de Amara Moira (2016); Vidas Trans: a coragem de existir, de T. Brant, Amara Moira, João W. Nery e Márcia Rocha (2017); Trinta anos de reclusão e as memórias de Porcina D'Alessandro, de Porcina D' Alessandro (2017); Nós, trans: escrevivências de resistência, organizada por Maria Léo Araruna (2017); A vida de um transgênero, de Téhh Queiroz (2018) e Velhice Transviada: memórias e reflexões, de João W. Nery (2019), identifico uma pauta reivindicativa dos direitos humanos.

Uma massa narrativa que, muito além de pautar a despatologização das identidades de pessoas trans e o direito ao autorreconhecimento, defende o seu pleno acesso aos direitos e garantias fundamentais e, por esse meio, cumpre um duplo e necessário papel: visibilizar as violências constitucionais históricas em nosso país quanto ao acesso aos direitos para essa parte de nossa população, e pautar a cisgeneridade como pilar do patriarcado cissexista, que tem servido para ordenar, classificar e subalternizar os gêneros em nossa sociedade e não apenas as pessoas transgêneras e intersexuadas (Jesus, 2014). Para demonstrar tal perspectiva nas obras, destaco em cada uma delas um direito constitucional violado, portanto, reivindicado, e vinculado ao princípio constitucional e jurídico da dignidade da pessoa humana - aberto e não taxativo ${ }^{16}$-, previsto no art. $1^{\circ}$, inciso III, da Carta Constitucional de 1988; um dos pilares do Estado Democrático de Direito, pois norteador de direitos e deveres em nossa sociedade (Falcão, 2013). Princípio configurado como básico, supremo e indispensável para que a vida humana seja minimamente reconhecida como digna, bem como fundamental nas relações em nossa sociedade, como define Ingo Wolfgang Sarlet (2002), pois se trata da

qualidade intrínseca e distintiva de cada ser humano que o faz merecedor do mesmo respeito e consideração por parte do Estado e da comunidade, implicando, neste sentido, um complexo de direitos e deveres fundamentais que assegurem a pessoa tanto contra todo e qualquer ato de cunho degradante e desumano, como venham a lhe garantir as condições existenciais mínimas para uma vida saudável, além de propiciar e promover sua participação ativa e co-responsável nos destinos da própria existência e da vida em comunhão com os demais seres humanos (p. 62).

Tomando como ponto de partida essas premissas, destaquei para cada uma das obras estudadas um direito negligenciado: o direito à parentalidade; o direito ao pertencimento comunitário; o direito à intimidade; o direito ao afeto; o direito à despatologização identitária; o direito ao aspecto físico da estética humana; o direito à infância; o direito à transição como processo; e o direito ao envelhecer.

Na obra de Nery (2011), composta de quatro partes, destaco a última, intitulada "Paternidade", em que o autor organiza o seu narrar-se pós-transição, o que inclui a sua experiência de paternidade como um homem trans numa sociedade transfóbica; uma temática também abrigada no penúltimo capítulo dessa parte, "O homem grávido", destinado a apresentar as pessoas trans como capazes de serem pais e mães biológicos, portanto, sujeitas e sujeitos do direito à parentalidade. Um pleito que, ainda na atualidade, é reconhecível como

\footnotetext{
${ }^{16}$ Aberto porque não admite um único conceito concreto e específico; não taxativo, porque admite ser interpretado extensivamente ou por analogias, não alcançando todas as situações que deve conter (Falcão, 2013).
} 
revolucionário em nossa sociedade, pois reivindicado por corpos transfobicamente não reconhecidos como dignos de constituição e vínculo familiar, conforme discutem Mônica Angonese e Mara Coelho de Souza Lago (2017).

Jô Lessa (2014) escreve a sua história de vida confirmando o quanto a invisibilização da transmasculinidade como uma identidade possível o impediu de existir como uma pessoa até os 45 anos de idade, comprometendo o seu reconhecimento enquanto sujeito com direito a uma existência nomeável como todo e qualquer cidadão, bem como uma pessoa com direito ao pertencimento comunitário:

Eu sou alguém que aos 45 anos de idade se viu diante de várias indagações, talvez nunca antes pensadas ou que já tivessem passado pela minha cabeça, porém, por achar as respostas tão malucas, tão fora de propósito calei aquela voz que gritava dentro do meu corpo (Lessa, 2014, p. 101).

Amanda Guimarães (2016), reconhecida como a primeira youtuber trans no Brasil, cuierlombolamente, usa o espaço autobiográfico para informar sobre direitos conquistados pela comunidade (uso do nome social e a garantia do processo transexualizador pelo Sistema Único de Saúde - SUS) e denunciar a violação de muitos outros, dentre eles o da intimidade, também protegido constitucionalmente. A violação de um direito que, ao fim e ao cabo, motivou-a a expor a sua história nas redes sociais e escrever a sua autobiografia, contribuindo para desnudar a banalização da transfobia em nossa sociedade.

Posso dizer que sofri piadinhas durante toda minha vida - e para falar a verdade ainda sofro com elas. Recebo diariamente xingamentos como trap, cilada, traveco, armadilha, homem capado, mulher kinder ovo, etc. Além disso, algumas pessoas me chamam de abominação (usando Deus como escudo), outras me mandam mensagens desejando que eu queime no inferno, chego a me sentir o anticristo! (p. 83).

Amara Moira (2016), avocando para si a identidade feminina travesti, aquela das identidades trans que mais tem sido estigmatizada e, consequentemente, violentada em nossa sociedade (Leite Júnior, 2012), rebeldemente garante pelo autobiográfico que a "travesti puta" também seja ouvida como uma "puta escritora": "Mas aguardem, o ataque às normas vai se intensificar por aqui: essa língua travesti puta escritora vai ser libertária ou não será" (Moira, 2016, p. 131):

Os homens de carne e osso não estão nos livros (fora esse aqui, claro), mas nus nos nossos quartos, de quatro, implorando pra pôr fim à farsa uns minutinhos que seja. Esse livro é o quê? Vingança podem pensar, mas não. Dão-me trocados pelo sexo que sei fazer e nem dão conta de o pagamento ser mais a história do que as moedas em si. [...] Soubessem disso os clientes, soubessem o que entregavam pra mim, que me vendiam a alma, talvez preferissem me pagar melhor... menos risco de aparecer nessas páginas (Moira, 2016, p. 201).

Nessa ocupação, a autora instala a denúncia de violação de mais um direito fundamental à dignidade da pessoa humana - o direito ao afeto -, como me ajudam a pensar os intérpretes jurídicos Edna Raquel Hogemann e Thiago Serrano Pinheiro de Souza (2013). Como discutem os estudiosos, não se trata do afeto reconhecido como um sentimento, mas como um direito fundamental em relação à vida social, pois mediador comunicacional determinante de um padrão comportamental humanitário vinculável ao princípio da solidariedade social, também com previsão constitucional.

Em Vidas trans: a coragem de existir (2017), Amara Moira, Márcia Rocha, João W. Nery e T. Brant instalam uma "manifestação" pelo direito ao autorreconhecimento de gênero - transição identitária -, inextrincavelmente vinculado à pauta da despatologização trans ancorada como agenda reivindicativa já na abertura da obra:

A transexualidade não é um transtorno, uma doença ou um problema psiquiátrico, pelo contrário. Na teoria, é algo mais simples: você não se identifica com o gênero que lhe designaram ao nascer. [...] É a isso que damos o nome de "identidade de gênero": a forma como as pessoas se entendem, independentemente da genitália (Brant et al., 2017, p. 10).

Uma manifestação igualmente voltada ao Supremo Tribunal Federal (STF), que justamente em 2017 inicia o julgamento da Ação Direta de Inconstitucionalidade (ADI) 4275, na qual se 
discutia a possibilidade de alteração de gênero no assento de registro civil sem a realização de procedimento cirúrgico de redesignação de sexo e laudo psiquiátrico.

Em Nós trans (2017), organizada por Maria Léo Araruna, a segunda obra coletiva deste corpus, constituída de 57 textualidades produzidas por 47 pessoas trans, deparamo-nos pelo volume reunido com o infanticídio de crianças gênero dissidentes. Como qualifica Maria Léo Araruna, um "amontoado de textos que acredita na potência dos encontros entre as/os marginais e na luta destas/es por transformações políticas sociais" (Araruna, 2017, p. 3). Importante salientar que, embora a violação da infância apareça em todas as obras deste corpus, demonstrá-la, por meio dessa obra, permite-me identificar essa violação como algo que se mantém inalterado em nossa sociedade há décadas, uma vez que autores e autoras de diferentes faixas etárias, condições socioeconômicas e raciais dão-nos a chave para acessar simultaneamente passado e presente tão perversamente iguais.

O livro de Porcina D’Alessandro (2017) me permite evidenciar a reivindicação de um direito ainda hoje violado para a população trans em nosso país: o direito ao aspecto físico da estética humana; um direito da personalidade, como discute o jurista Rubens Limongi França (1983) e, portanto, vinculado ao princípio da dignidade da pessoa humana. Como destaca Aureliano Silva Júnior (2018), a construção estética da feminilidade e da masculinidade é determinante no processo de autoidentificação e no de construção de um sentimento de pertença trans binário, que não vem apenas de si, mas de uma identificação e validação pelo outro. Direito humano que é reivindicado no testemunho de D'Alessandro (2017), marcado pela assunção do uso abusivo de silicone líquido industrial (SLI) para construir a sua "mulheridade", assim como pelo negócio rentável, na década de 1990, que a transformou numa "bombadeira", ou seja, aquela que passou a fazer aplicações de silicone no corpo de outras mulheres e por isso levada a julgamento pelo Estado.

Téhh Queiroz (2018), ao publicitar a sua transição de gênero aos 24 anos de idade, decide arquivar sua jornada de autoidentificação colocando em xeque anamneses médicas que, via de regra, homogeneizam a experiência da transição de gênero como uma trajetória teleológica, ou seja, entre a origem e o destino, uma jornada de certezas absolutas por parte de quem o vive; viés de "compreensão" que historicamente, e ainda hoje, vem sendo usado para deslegitimar e patologizar sujeitos e sujeitas que se colocam em questionamento quanto aos desconfortos da vivência compulsória de gênero. Uma perspectiva narrativa libertária, pois permite identificar a defesa do direito ao processo de definição de gênero como "em definição".

Na última obra deste nucleamento, João W. Nery (2019) pauta o direito ao envelhecimento como um direito humano ainda inacessível para a maior parte das pessoas trans em nosso país; o que se realiza tanto por narrar o seu envelhecer, uma conquista, apesar de todas as violências sofridas, quanto pelo espaço que garante para arquivar o envelhecer de outras pessoas trans idosas - exceção no país que mais mata mulheres trans no mundo (ANTRA, 2019; ANTRA, 2020). Como enfatiza o autor, "tinha que dar continuidade aos depoimentos, ecoar a voz das pessoas amordaçadas por essa sociedade hipócrita, que só ouve o discurso estereotipado que lhe é conveniente" (Nery, 2019, p. 81). Também por este aspecto a obra de Nery (2019) ganha um sentido muito significativo neste trabalho, uma vez que, após ter escrito três obras autobiográficas, promove por meio desta quarta - coincidentemente a última a compor esta ocupação e a última que escreveu - a instalação de uma temática que "encerra" um ciclo de vida, o qual deveria ser garantido para toda a população de nosso país.

\section{Convite para alianças}

Por todo o exposto, o levante cuíerlombista, configurado nas produções de autoria trans, coloca-se, sobretudo, como convite para alianças, uma vez que, ao desnudar a vulnerabilidade corporal de determinadas vidas em nossa sociedade, se, por um lado, interpela-nos, a cisgeneridade, quanto a nossa responsabilidade neste cistema mortal; por outro, permite-nos indagar sobre os efeitos perversos da compulsoriedade de gênero e sexualidade sobre todas e todos nós. Pelos aspectos destacados e por toda a sua potencialidade literária, ainda 
negligenciada pelos estudos literários cisheteronormativadores, esse levante revela-se como uma força imprevista pelo e no campo literário, permitindo-nos compreender que só poderemos perdurar sob processos e movimentos democráticos num mundo que seja sustentado e sustentável por coligações e alianças, pois uma sociedade boa e justa é uma sociedade boa e justa para todas e todos (Butler, 2018).

\section{Referências}

ÁDREON, Loris (1985). Meu corpo, minha prisão: autobiografia de um transexual. Rio de Janeiro: Marco Zero.

ANGONESE, Mônica; LAGO, Mara Coelho de Souza (2017). Direitos e saúde reprodutiva para a população de travestis e transexuais: abjeção e esterilidade simbólica. Saúde e sociedade, São Paulo, v. 26, n. 1, p. 256-270, mar. Disponível em: https:/ / bit.ly/3ngvFhq. Acesso em: 4 jun. 2020.

ANTRA - ASSOCIAÇÃO NACIONAL DE TRAVESTIS E TRANSEXUAIS (2009). Assembleia da ANTRA, Teresina - PI, maio. Disponível em: https:/ /antrabrasil.org/assassinatos. Acesso em: 3 mar. 2020.

ANTRA - ASSOCIAÇÃO NACIONAL DE TRAVESTIS E TRANSEXUAIS (2019). Mapa dos assassinatos de travestis e transexuais no Brasil em 2018. Disponível em: https:/ / bit.ly/3powuHG. Acesso em: 9 ago. 2019.

ANTRA - ASSOCIAÇÃO NACIONAL DE TRAVESTIS E TRANSEXUAIS (2020). Mapa dos assassinatos de travestis e transexuais no Brasil em 2019. Disponível em: https:/ / bit.ly/3ndKscv. Acesso em: 20 mar. 2020.

ARARUNA, Maria Léo (org.) (2017). Nós, trans: escrevivências de resistência. São Paulo: LiteraTrans.

BRANT, T. et al. (2017). Vidas trans: a coragem de existir. São Paulo: Astral Cultural.

BUTLER, Judith (2018). Corpos em aliança e a política das ruas: notas para uma teoria performativa de assembleia. Rio de Janeiro: Civilização Brasileira.

CARVALHO, Maria Luiza Moura de (2018). A retificação do registro civil de pessoas transgênero na América do Sul em perspectiva comparada. Revista da Faculdade de Direito da UFRGS, Porto Alegre, v. esp., n. 39, p. 67-91, dez.

CHAVES, Leocádia Aparecida (2021). A escrita autobiográfica trans como estratégia de resistência e organização: vaga-lumes na escuridão de nosso tempo. Tese (Doutorado em Literatura) - Universidade de Brasília, Brasília.

COLLINS, Patricia Hill (2019). Pensamento feminista negro. Tradução de Jamille Pinheiro Dias. São Paulo: Boitempo.

DALCASTAGNÈ, Regina (2005). A personagem do romance brasileiro contemporâneo (1990-2004). Estudos de Literatura Brasileira Contemporânea, Brasília, n. 26, p. 13-71.

DALCASTAGNÈ, Regina (2012). Literatura brasileira contemporânea: um território contestado. Rio de Janeiro: Editora da UERJ; Horizonte.

DALCASTAGNÈ, Regina (2021). Ausências e estereótipos no romance brasileiro das últimas décadas: alterações e continuidades. Letras de hoje, Porto Alegre, v. 56, n. 1, p. 109-143, jan.-abr. Disponível em: https://revistaseletronicas.pucrs.br/index.php/fale/article/view/40429/26848. Acesso em: 20 ago. 2021.

D'ALESSANDRO, Porcina (2017). Trinta anos de reclusão e as memórias de Porcina D'Alessandro. São Paulo: LiteraTrans.

DAS, Veena (2007). Life and words: violence and the descent into the ordinary. Berkeley: University of California Press.

FALCÃO, Valdirene Ribeiro de Souza (2013). Os direitos fundamentais e o princípio da dignidade da pessoa humana. Revista da SJRJ - Direito Processual Civil, v. 20, n. 38, p. 227-239.

FRANÇA, Rubens Limongi (1983). Direitos da personalidade. Revista dos Tribunais, São Paulo, n. 567, p. 0916 , jan.

GAUDENZI, Paula (2018). Intersexualidade: entre saberes e intervenções. Cad. Saúde Pública, Rio de Janeiro, v. 34, n. 1. Disponível em: https:/ /bit.ly/3B6furM. Acesso em: 18 set. 2020. 
GOFFMAN, Erving (1988). Estigma: notas sobre a manipulação da identidade deteriorada. Rio de Janeiro: Zahar. GUIMARÃES, Amanda (2016). Meu nome é Amanda: \#trans\#mandycandy\#youtube. Rio de Janeiro: Rocco. HERZER, Anderson (2007). A queda para o alto. 25. ed. São Paulo: Vozes.

HOGEMANN, Edna Raquel; SOUZA, Thiago Serrano Pinheiro de (2013). O direito fundamental ao afeto. RIDH, Bauru, v. 1, n. 1, p. 67-88, dez.

HOOKS, Bell (2019a). Olhares negros, raça e representação. Tradução de Sthephanie Borges. São Paulo: Elefante.

HOOKS, Bell (2019b). O feminismo é para todo mundo: políticas arrebatadoras. Tradução de Bhuvi Libânio. Rio de Janeiro: Rosa dos Tempos.

JESUS, Jaqueline Gomes de (2010). Pessoas transexuais como reconstrutoras de suas identidades: reflexões sobre o desafio do direito ao gênero. In: SIMPÓSIO GÊNERO E PSICOLOGIA SOCIAL DIÁLOGOS INTERDISCIPLINARES, 2010, Brasília. Anais [...]. Brasília: Universidade de Brasília. Disponível em: https:// bit.ly/3aVkpkG. Acesso em: 14 mar. 2019.

JESUS, Jaqueline Gomes de (2013). Transfobia e crimes de ódio: assassinatos de pessoas transgênero como genocídio. In: MARANHÃO FILHO, Eduardo Meinberg de Albuquerque (org.). (In)Visibilidade Trans 2. História Agora, v. 16, n. 2, p. 101-123.

JESUS, Jaqueline Gomes de (2014). Gênero sem essencialismo: feminismo transgênero como crítica do sexo. Universitas Humanística, Bogotá, n. 78, p. 241-258, jul./dez.

LAURETIS, Teresa de (1991). Queer theory: lesbian and gay sexualities. Special issue of diferences: A Journal of Feminist Cultural Studies, v. 3, n. 2, Summer.

LEITE JÚNIOR, Jorge (2012). Transitar para onde?: monstruosidade, (des)patologização, (in)segurança social e identidades transgêneras. Revista de Estudos Feministas, Florianópolis, v. 20, n. 2, p. 559-568. Disponível em: http://dx.doi.org/10.1590/S0104-026X2012000200016. Acesso em: 18 mar. 2019.

LEJEUNE, Philippe (2014). O pacto autobiográfico: de Rousseau a internet. 2. ed. Tradução de Jovita Noronha e Maria Inês Guedes. Belo Horizonte: Editora UFMG.

LESSA, Jô (2014). Eu trans: a alça da bolsa - Relatos de um transexual. Rio de Janeiro: Metanóia.

LONG, Norman; PLOEG, Jan Douwe van der (2011). Heterogeneidade, ator e estrutura: para a reconstituição do conceito de estrutura. In: SCHNEIDER, Sérgio (org.). Os atores do desenvolvimento rural, perspectivas teóricas e práticas sociais. Porto Alegre: UFRGS. p. 21-48.

LORDE, Audre (2020). Irmã outsider. Belo Horizonte: Autêntica.

MARCUSCHI, Luiz Antônio (2005). Gêneros textuais: definição e funcionalidade. In: DIONISIO, Angela Paiva; MACHADO, Ana Rachel; BEZERRA, Maria Auxiliadora (org.). Gêneros textuais e ensino. Rio de Janeiro: Lucerna. p. 19-36.

MOIRA, Amara (2016). E se eu fosse puta. São Paulo: Hoo editora.

MOIRA, Amara (2018). Monstruoso corpo de delito: personagens transexuais na literatura brasileira. Suplemento Cultural do Diário Oficial do Estado, s/1, 10 dez. Disponível em: https://bit.ly/3G8cOxC. Acesso em: 10 jan. 2019.

MOIRA, Amara (2019). Entrevista com Amara Moira. [Entrevista concedida a] Nana Deluca e Caio Jade Puosso. Revista Crioula, São Paulo, n. 24, p. 246-249, $2^{\circ}$ sem. Disponível em: https://bit.ly/3niWzoZ. Acesso em: 20 mar. 2020.

NASCIMENTO, Abdias do (1980/2002). O quilombismo. 2. ed. Brasília: Fundação Palmares; Rio de Janeiro: OR Editor Produtor. Disponível em: https:// bit.ly/3vw2udZ. Acesso em: 14 mar. 2019.

NASCIMENTO, Beatriz (2006). O conceito de quilombo e a resistência cultural negra. In: RATTS, Alex de. Eu sou atlântica: sobre a trajetória de vida de Beatriz Nascimento. São Paulo: Imprensa Oficial; Instituto Kwanza. p. 117-125. Disponível em: https://bit.ly/3DWpyoY. Acesso em: 5 out. 2018.

NASCIMENTO, Tatiana (2018a). O cuíerlombo da palavra (y da palavra queerlombo...) > poesia preta lgbtqi de denúncia da dor até direito ao devaneio. In: ARAÚJO, Adriana de Fátima Barbosa; SOUTO, Suzana (org.) I Encontro Ler: literatura, estética e revolução. Brasília: Universidade de Brasília. p. 8-23. 
NASCIMENTO, Tatiana (2018b). Da palavra queerlombo ao cuíerlombo da palavra. Palavra, preta! poesia di dendê, 12 mar. Disponível em: https://palavrapreta.wordpress.com/2018/03/12/cuierlombismo/. Acesso em: 23 out. 2019.

NASCIMENTO, Tatiana (2019). Leve sua culpa branca pra terapia. Brasília: Padê Editorial.

NERY, João W. (1984). Erro de pessoa: Joana ou João?: o depoimento de um transexual brasileiro que, nascido mulher, finalmente se realizou como homem. Rio de Janeiro: Record.

NERY, João W. (2011). Viagem solitária: memórias de um transexual trinta anos depois. São Paulo: Leya.

NERY, João W. (2019). Velhice transviada: memórias e reflexões. Rio de Janeiro: Objetiva.

PRECIADO, Paul Beatriz (2020). Um apartamento em Urano: crônicas da travessia. Rio de Janeiro: Zahar.

QUEIROZ, Téhh (2018). A vida de um transgênero. Paraná: Viseu.

QUINALHA, Renan (2021). Contra a moral e os bons costumes: a ditadura e a repressão à comunidade LGBT. São Paulo: Companhia das Letras.

RUDDY (1998). Liberdade ainda que profana. Rio de Janeiro: Razão Cultural.

RUDDY PINHO (2007). Nem tão bela, nem tão louca. Rio de Janeiro: Razão Cultural.

SARLET, Ingo Wolfgang (2002). Dignidade da pessoa humana e direitos fundamentais na Constituição Federal de 1988. 2. ed. Porto Alegre: Livraria do Advogado.

SCHWANTES, Cíntia; CHAVES, Leocádia Aparecida (2019). Sob um sistema literário desigual e violento, frestas: a presença de personagens e escritores trans na literatura contemporânea brasileira do século XXI. In: BELISÁRIO, Kátia Maria; MOURA, Dione O.; GUAZINA, Liziane. (org.). Gênero em pauta: desconstruindo violências, construindo novos caminhos. Curitiba: Appris. v. 1.

SILVA, Tomaz Tadeu da. A produção social da identidade e da diferença (2014). In: SILVA, Tomaz Tadeu da (org.). Identidade e diferença: a perspectiva dos estudos culturais. Rio de Janeiro: Vozes. p. 73-102.

SILVA JÚNIOR, Aureliano Lopes da (2018). Feminização, estigma e o gênero facializado: a construção moral do gênero feminino por meio de cirurgias de feminização facial para travestis e mulheres transexuais. Saúde soc., São Paulo, v. 27, n. 2, p. 464-480, jun. Disponível em: https://bit.ly/3plrzXN. Acesso em: 24 jun. 2020.

SIQUEIRA, Indianarae (2017). Visibilidade trans: lutar, resistir e reexistir! Psol, 30 jan. Disponível em: https:/ / psol50.org.br/indianara-siqueira-visibilidade-trans-lutar-resistir-e-reexistir/. Acesso em: 7 maio 2021.

SOARES, Luiz Henrique Moreira; LOPES, Rosiney Aparecida (2017). Ela é amapô de carne, osso e palavras: personagens travestis no romance contemporâneo brasileiro. Revista do Instituto de Políticas Públicas de Marília, v. 3, n. 1, p. 79-96, jan./jun. Disponível em: https:/ / bit.ly/2Zbvcoo. Acesso em: 30 ago. 2017.

SPIVAK, Gayatri (2010). Pode o subalterno falar? Tradução de Sandra Regina Goulart Almeida, Marcos Pereira Feitosa e André Pereira Feitosa. Belo Horizonte: Editora UFMG.

TREVISAN, João Silvério (2018). Devassos no paraíso: a homossexualidade no Brasil da colônia à atualidade. Rio de Janeiro: Objetiva.

VERGUEIRO, Viviane Simawaka (2015). Por inflexões decoloniais de corpos e identidades de gênero inconformes: uma análise autoetnográfica da cisgeneridade como normatividade. Dissertação (Mestrado em Cultura e Sociedade) - Universidade Federal da Bahia, Salvador.

WONDER, Claudia (2008). Olhares de Claudia Wonder: Crônicas e outras histórias. São Paulo: GLS.

\section{Nota}

Este artigo deriva da tese de minha autoria intitulada A produção autobiográfica de autoria trans no Brasil contemporâneo como estratégia de resistência e organização: vaga-lumes na escuridão de nosso tempo, defendida em 2021, na Universidade de Brasília. 